\title{
Science budget falling behind
}

\section{Cape Town}

RESEARCH prospects in South Africa are looking bleak. Although next year's budget has yet to receive formal approval, the Council for Scientific and Industrial Research (CSIR) is expecting an increase of at most 4 per cent. With inflation running at 15 per cent, and research costs hit further by the weak rand, significant cutbacks are inevitable. Even so, science and education seem to be relatively welltreated by the de Klerk government, which is making a concerted effort to curb state spending; a 15 per cent cut in the defence budget, for example, has been suggested.

Worst affected has been the CSIR's Foundation for Research Development (FRD), whose responsibility its head, Rhein Arndt, describes as "manpower development in science and technology".

This includes the funding of university research and the provision of student grants. Last year, the CSIR's national SPACE AGENCY

\section{Arianespace forced to twiddle thumbs \\ Paris}

TeCHNICAL problems, small print and the San Francisco earthquake have left Arianespace, Europe's commercial satellite launch consortium, with nothing to launch this month, despite a full order book and a tight schedule.

Originally, the French SPOT 2 commercial Earth observation satellite - the overdue replacement for the successful but ageing SPOT 1 - was scheduled for launch last month. But 'technical problems' with the Ariane 40 rocket led Arianespace to delay the Flight 35 launch until December, pending further tests.

However, the Superbird A satellite, built by Ford Aerospace for the Japanese, was also scheduled for a December launch and a postponement would have incurred penalties for Arianespace.

So the consortium asked the French national space research centre (CNES), which owns SPOT, to let the Japanese satellite go up first.

Because Spot 1 is still sending pictures, Spot 2 was rescheduled for launch on 10 January. In the meantime, Superbird A, which was undergoing final tests at Ford Aerospace in Palo Alto, was shaken by the San Francisco earthquake, and the manufacturers decided it would be unwise to send the satellite to the Kourou launch site without more tests. As Spot 2 could not be taken out of wraps again at short notice, this has left Ariane-space with two launchers ready to go, but no payload.

Peter Coles laboratories were taken from FRD and given to another arm of CSIR, Research, Development and Implementation (RDI) (see Nature 332, 197; 1988). The aim was to move towards 'near-market' research, and the RDI has been successful in supporting research with contracts from government departments and the private sector. Last year, 38.8 per cent of the CSIR's income was derived from outside contracts, and this is expected to rise to 41.5 per cent this year. In compensation for this move, the FRD expected to get more of the CSIR's overall budget as the RDI became more self-financing. But this has not happened: this year, FRD was allocated the same proportion of total government support as last, and no change is expected in the coming year. The net effect has therefore been a shift of money from basic to applied research.

Although the CSIR's grant is negotiated from the Treasury by the Ministry of Trade, Industry and Tourism, the RDI and the FRD budgets are considered to be separate entities, and are dictated by the government. The cabinet is currently considering a request by the FRD to be moved to the national education budget, which is in the hands of Minister Gerrit Viljoen. $\mathrm{He}$ is more enthusiastic about basic research, and also seems to have the ear of President F. W. de Klerk.

The FRD also runs the country's four national research facilities: the South African Astronomical Observatory, the Radio Astronomy Observatory, the Magnetic Observatory and the National Accelerator Centre (NAC). Last year, NAC alone cost CSIR R30 million ( $\$ 12$ million), 34 per cent of the CSIR budget, and many of the country's scientists feel that NAC is an under-used and unaffordable luxury.

Last month, FRD initiated an independent review, by scientists from outside South Africa of the quality of work being carried out at NAC, its impact on the development of technical expertise in South Africa, and NAC's place in the country's science system. Arndt says that the future of NAC is "something that the science community will have to take a hard decision on".

At the root of all these problems is the small proportion of gross domestic product (GDP) that South Africa spends on research and development. In 1987, research and development spending from all sources amounted to 1 per cent of GDP ( $\mathrm{R} 1,700$ million, or $\$ 700$ million), with roughly equal amounts coming from government and the private sector. This is a much smaller proportion than is spent by Britain or France (2.3 per cent of GDP in $1987)$, and is less even than India (1.1 per cent).
Technical studies to be compulsory

\section{Sydney}

AN ambitious reform of the education system in New South Wales will make the study of mathematics, science and technology compulsory for high school students in the province. Under the present system, the only compulsory subject for final year students taking their Higher School Certificate is English, but by 1992, following the introduction of the government's white paper (policy document) on curriculum reform, students will also have to take at least one technical course.

Until now teachers have been providing courses in technology and computing, of a mostly vocational nature, under a category known as Other Approved Studies (OAS). The government intends to reduce the OAS from 10,000 to 500 subjects, substituting new technology courses instead. The white paper will also make it compulsory for 13-15 year-olds to study a language and a technology course. In other changes to the curriculum, courses involving AIDS and drug education will be integrated into a new mandatory health and physical education programme.

The government acknowledges that the major difficulty in the introduction of these reforms is a shortage of teachers of technology, science and mathematics. A spokesperson for the Minister for Education said that the department would be negotiating with the NSW Teachers' Federation for a salary increase for staff in these fields. But the teachers are unlikely to go along with such changes. Sue Simpson, spokesperson for the NSW Teachers' Federation, said she found the suggestion of differential rates of pay surprising, and argued instead for "an overall increase in teachers' salaries to entice teachers back into the system".

Tania Ewing

\section{ASTRONOMY FROM SPACE Solar max falls at last}

\section{Washington}

THE Solar Maximum Mission satellite (SMM), launched in 1980 to observe flares and other activity during the peak of the last solar cycle, almost survived until the peak of the present solar cycle, expected in about four months. But last Sunday morning, 3 December, it re-entered the Earth's atmosphere and burned up over the Indian Ocean near Sri Lanka. In 1984, SMM became the first satellite to be successfully retrieved, repaired and returned to orbit by the crew of a space shuttle mission. SMM's swansong was its observation of gammarays from Supernova 1987 A, which provided the first observational confirmation that supernovae remnants are powered for the first year or so by the radioactive decay of ${ }^{56} \mathrm{Ni}$ synthesized in the initial explosion (see Nature 331, 416; 1989). David Lindley 